\title{
Effects of retrieving childhood events on metamemory judgments depend on the questions you ask
}

Citation for published version (APA):

Merckelbach, H. L. G. J., Wiers, R. W. H. J., Horselenberg, R., \& Wessel, J. P. (2001). Effects of retrieving childhood events on metamemory judgments depend on the questions you ask. British Journal of Clinical Psychology, 40, 215-220. https://doi.org/10.1348/014466501163553

Document status and date:

Published: 01/01/2001

DOI:

10.1348/014466501163553

Document Version:

Publisher's PDF, also known as Version of record

\section{Please check the document version of this publication:}

- A submitted manuscript is the version of the article upon submission and before peer-review. There can be important differences between the submitted version and the official published version of record.

People interested in the research are advised to contact the author for the final version of the publication, or visit the DOI to the publisher's website.

- The final author version and the galley proof are versions of the publication after peer review.

- The final published version features the final layout of the paper including the volume, issue and page numbers.

Link to publication

\footnotetext{
General rights rights.

- You may freely distribute the URL identifying the publication in the public portal. please follow below link for the End User Agreement:

www.umlib.nl/taverne-license

Take down policy

If you believe that this document breaches copyright please contact us at:

repository@maastrichtuniversity.nl

providing details and we will investigate your claim.
}

Copyright and moral rights for the publications made accessible in the public portal are retained by the authors and/or other copyright owners and it is a condition of accessing publications that users recognise and abide by the legal requirements associated with these

- Users may download and print one copy of any publication from the public portal for the purpose of private study or research.

- You may not further distribute the material or use it for any profit-making activity or commercial gain

If the publication is distributed under the terms of Article $25 \mathrm{fa}$ of the Dutch Copyright Act, indicated by the "Taverne" license above, 


\title{
Brief report \\ Effects of retrieving childhood events on metamemory judgments depend on the questions you ask
}

\author{
Harald Merckelbach*, Reinout Wiers, Robert Horselenberg and Ineke Wessel \\ Maastricht University, The Netherlands
}

\begin{abstract}
Objective. The more people retrieve childhood memories, the less favourably they evaluate their own memory. It has been argued that this might play a role in selfreports of amnesia. However, a limitation of previous studies addressing this phenomenon is that participants' judgments about their memory were based on a single item.
\end{abstract}

Design. Students were randomly assigned to either of two conditions. In one condition, they were asked to retrieve nine negative childhood events, whereas in the other condition, participants were required to recall three events.

Method. After recall, students completed measures on memory accessibility and 'repression'.

Results. Students who retrieved nine events rated their memories as less accessible, but also reported less repression than did students who retrieved three events.

Conclusion. The direction of retrieval effects on metamemory judgments depends on the way in which questions are framed.

In a recent study, Winkielman, Schwarz, and Belli (1998) examined the effects of retrieving childhood events on participants' judgments about memory completeness. Basically, these researchers asked undergraduate students to recall either 12 or 4 childhood events. Next, students answered a single metamemory item that was taken from a clinical interview to diagnose dissociative phenomena such as amnesia. More specifically, the pertinent item was as follows: 'Are there large parts of your childhood after age 5 which you can't remember?' (Ross, 1997, p. 394). Response options were 'yes', 'no' or 'unsure'. In the 12-events condition, a higher percentage of participants $(46 \%)$ endorsed the 'yes' option than in the four-events condition (19\%), which led the

* Requests for reprints should be addressed to Harald Merckelbach, Department of Experimental Psychology, Maastricht University, PO Box 616, 6200 MD Maastricht, The Netherlands (e-mail: H.Merckelbach@psychology.unimaas.nl). 
authors to conclude that 'the sheer attempt to recall a large amount of material may result in inferences of poor memory, even when the recall attempt is successful' (Winkielman et al., 1998, p. 126). In two further experiments, Belli, Winkielman, Read, Schwarz, and Lynn (1998) replicated the paradoxical effect of retrieval on judgments of memory completeness. Moreover, these authors demonstrated that this effect is mediated by experienced difficulty. That is, participants who are asked to retrieve many childhood events will misattribute the difficulty of this task to the poor quality of their memory. Belli and co-workers (1998) are also quite explicit about the implications they see for clinical practice: 'The findings challenge the validity of reports of childhood amnesia that follow memory recovery' (p. 318).

Certainly, the studies cited above are innovative in that they address the link between retrieval effort and metamemory judgments. In doing so, they may shed new light on self-reports of amnesia in the clinical context. However, before the results from this research line can be generalized to the clinical domain, two points should be considered. To begin with, the studies cited above asked normal participants to retrieve memories of childhood events without specifying the affective tone (e.g. aversive or neutral) of these memories. Yet, in the clinical context, dissociative amnesia for autobiographical material is often related to the highly aversive nature of the events involved (e.g. Joseph, 1999). Thus, the question arises what happens when participants are invited to retrieve many aversive childhood events. Would the paradoxical effect of retrieval on memory completeness estimates occur under that condition?

Secondly, the studies cited above all relied on a single item to tap judgments about memory completeness, namely 'are there large parts of your childhood after age 5 which you can't remember?'. Responding with 'yes' to this item may have little to do with amnesia as it is portrayed by clinicians or cognitive psychologists (e.g. Brewin, 1998). One could even make the case that the only sensible answer to this item is 'yes' given the fact that memory loss is a perfectly normal phenomenon (Riccio, Rabinowitz, \& Axelrod, 1994). What would happen if people are directly asked about amnesia after they have retrieved many or only a few negative childhood events? Of course, the majority of them would probably not understand the fairly technical term of amnesia, but one could ask them about 'repression', which is a common term often used as an equivalent of amnesia (e.g. Pope \& Hudson, 1995). The current study sought to explore both issues. Thus, participants were asked to retrieve nine or three negative childhood events and following this they had to answer two items: one about memory accessibility, and the other about repression. A subsidiary aim of the present study was to explore to what extent metamemory judgments are affected by certain individual difference variables. More specifically, we asked participants to complete measures of dissociativity and fantasy proneness, traits that are often referred to in literature about memory recovery and amnesia (e.g. Spanos, Burgess, Burgess, Samuels, \& Blois, 1999).

\section{Method}

Undergraduate medical or health sciences students $(N=52)$ volunteered to participate in the experiment. All were women and their mean age was 21 years (range: 18-31 years). Participants were randomly assigned to one of two conditions. In the first condition, participants were asked to write down three different negative autobiographical events that took place before the age of 10 . They had to specify briefly the content ('what happened?'), the place ('where did it happen?'), and the actors involved ('who 
was involved?'). Using the same format, participants in the second condition had to retrieve and write down nine different aversive events that took place before the age of 10 .

After the participants had written down their childhood memories, they were asked to what extent they agreed with the items 'many of my childhood memories are difficult to access' and 'I have repressed many of my childhood memories'. Both items were scored on $100 \mathrm{~mm}$ Visual Analogue Scales (VASs: anchors: 0 = I strongly disagree; $100=$ I fully agree).

Following this, participants were asked to complete the 28-item Dissociative Experiences Scale (DES: Bernstein \& Putnam, 1986; Cronbach alpha $=.92$ ), the 25-item Creative Experiences Questionnaire (CEQ: Merckelbach, Muris, \& Rassin, 1999; Cronbach alpha =.75), and the 48-item Inventory of Childhood Memories and Imaginings (ICMI: Myers, 1983; Cronbach alpha $=.83$ ). The first scale is a measure of dissociativity, while the latter two questionaires intend to tap a trait known as fantasy proneness (i.e. the tendency to engage in daydreaming and vivid imaginal activities). The CEQ is a brief, Dutch index of fantasy proneness, while the ICMI is a more extensive and widely used scale for this purpose.

\section{Results}

Table 1 shows mean ratings of memory accessibility and repression as well as mean DES, CEQ, ICMI scores for participants in the two conditions. There were no differences between the two groups with regard to dissociativity (i.e. DES) or fantasy proneness (i.e. CEQ and ICMI): all ts < 1.7; all ps > .09, two-tailed. As can be seen, participants who were instructed to retrieve nine childhood events found their childhood memories less accessible than participants who had to retrieve only three events $(t(50)=2.1, p<$ .05 , two-tailed). In contrast, participants in the nine-events condition reported less repression of childhood memories than participants in the three-events condition $(t(50)=2.2, p<.05$, two-tailed $)$.

In the nine-events condition, four participants wrote down less than nine childhood events. To rule out the possibility that these participants heavily contributed to the findings reported above, analyses were repeated after excluding their data, leaving 22 participants in the nine-events condition. Basically, a similar pattern of results was obtained. That is, nine-events participants found their memories less accessible $(t(46)=2.0, p<.05)$, but also tended to report less repression $(t(46)=1.9, p=.06)$ than three-events participants.

VAS ratings of childhood memory accessibility did not correlate with VAS ratings of repression (Pearson $r=.15$, n.s.). Furthermore, dissociation scores (DES) did not correlate with metamemory VAS judgments (both $r<.17$, n.s.). Scores on the fantasy proneness scales (CEQ and ICMI) were strongly correlated with each other $(r=.77$, $p<.01)$ and with DES $(r=.65$ and $r=.57$; both $p$ s $<.01)$, but were not related to metamemory VAS judgments about repression (both $r$ s $<.02$, n.s.). However, both fantasy proneness scales were negatively linked to judgments about memory accessibility (both $r \mathrm{~s}>-.41$, both $p \mathrm{~s}<.01$ ), indicating that the higher participants scored on fantasy proneness, the more strongly they disagreed with the item that 'many of my childhood memories are difficult to access'.

\section{Discussion}

Participants who had retrieved and written down nine childhood events rated their memory accessibility in less favourable terms than did participants who had retrieved only three childhood events. Thus, although we asked participants to retrieve negative 
Table 1. Mean dissociation (DES) and fantasy proneness (CEQ and ICMI) scores and average ratings on $100 \mathrm{~mm}$ Visual Analogue Scales of difficulty to access childhood memories and of repression of childhood memories in the nine-events condition $(N=26)$ and in the three-events condition $(N=26)$

Condition

Three events

$19.2(12.2)$

DES

CEQ

ICMI

Lack of accessibility

Repression
$7.5(4.5)$

$18.8(8.6)$

$51.2(27.0)$

$29.9(27.8)$
Nine events

$14.9(8.3)$

$5.7(2.3)$

$16.6(4.5)$

$65.9(22.3)$

$15.6(19.2)$

Note. Standard deviations are given in parentheses.

rather than neutral childhood events, the results we obtained for subjective accessibility estimates closely parallel the paradoxical phenomenon described by Winkielman et al. (1998). These authors noted that the more events participants are required to retrieve, the more often these participants conclude that they are unable to remember large parts of their childhood. In previous studies (Belli et al., 1998; Winkielman et al., 1998), it was argued that this paradoxical effect of retrieval on metamemory judgments might be responsible for certain forms of self-reported amnesia. However, our findings suggest that there might be important limiting conditions to the paradoxical effects of retrieval. That is, when explicitly asked about repression, participants who had retrieved and written down nine negative childhood events were less likely to believe that they had repressed their childhood memories than participants who had retrieved only three childhood events. Apparently, then, effects of retrieval on metamemory judgments depend on the question you ask. This casts doubts on earlier attempts (Belli et al., 1998; Winkielman et al., 1998) to generalize the paradoxical effect of retrieval to clinical situations in which patients claim to have 'repressed' and then recovered certain memories. The fact that scores on a clinical screening instrument such as the DES do not correlate with metamemory judgments further underlines this point.

As Winkielman et al. (1998) pointed out, metamemory judgments might be biased by two related types of retrieval information. One type has to do with the difficulty of retrieving childhood memories, while the other has to do with the content of such memories. Attempts to retrieve a large number of autobiographical events might have a paradoxical effect to the extent that metamemory judgments are framed in terms of difficulty of recall, accessibility of memories, and so forth. Yet, such attempts may not have a paradoxical effect when metamemory judgments are explicitly framed in terms of content. Clearly, metamemory judgments about amnesia and repression heavily draw on the absence or presence of memory content. Our findings seem to indicate that the more memory content is retrieved, the less likely people are to believe that they have repressed childhood memories. At a more theoretical level, Schwarz (1998) noted that people will tend to rely on memory content rather than experienced difficulty when they have to 
form judgments about highly technical and/or self-relevant issues. We suspect that asking people whether they have repressed childhood memories is confronting them with an issue that is both technical and self-relevant and this may explain why the paradoxical effect of retrieval does not occur with such an item.

One limitation of the present study is that it relied on a sample of women. Thus, sex differences in retrieval effects on metamemory judgments cannot be ruled out. On the other hand, it should be emphasized that the paradoxical effects of retrieval have been claimed to bear relevance to the clinical phenomena of amnesia and recovered memories (e.g. Belli et al., 1998). Given the fact that these phenomena predominantly occur in women (e.g. Gudjonsson, 1997), our findings are informative because they show that, at least in women, paradoxical effects of retrieval depend on the questions asked. A second limitation of the present study and previous studies (e.g. Belli et al., 1998) is that crucial terms ('accessibility', 'repression', 'large parts of your childhood') that figure in metamemory judgments are not defined. Thus, we have no way of knowing with what definition in mind participants made their metamemory judgments. Future research on the links between retrieval and metamemory judgments should preferably include a large set of a priori defined metamemory items, with some of them referring to recall difficulty and others addressing current and past memories for content. Such parametric research may help to identify the precise conditions under which repeated retrieval produces judgments of 'poor' childhood memories. The current findings also suggest that it might be worthwhile to look at the contribution of certain individual difference variables to metamemory judgments. In particular, elevated scores on fantasy proneness seem to be related to optimistic judgments about memory accessibility. Thus, it is conceivable that such individual difference variables modulate the connection between retrieval and metamemory judgments.

\section{References}

Belli, R. F., Winkielman, P., Read, J. D., Schwarz, N., \& Lynn, S. J. (1998). Recalling more childhood events leads to judgments of poorer memory: Implications for the recovered/false memory debate. Psychonomic Bulletin and Review, 5, 318-323.

Bernstein, E., \& Putnam, F. W. (1986). Development, reliability, and validity of a dissociation scale. Journal of Nervous and Mental Disease, 174, 727-735.

Brewin, C. R. (1998). Commentary: Questionable validity of dissociative amnesia in trauma victims. British Journal of Psychiatry, 172, 216-217.

Gudjonsson, G. H. (1997). Accusations by adults of childhood sexual abuse: A survey of the members of the British False Memory Society (BFMS). Applied Cognitive Psychology, 11, 3-18.

Joseph, R. (1999). The neurology of traumatic dissociative amnesia: Commentary and literature review. Child Abuse and Neglect, 8, 715-727.

Merckelbach, H., Muris, P \& Rassin, E. (1999). Fantasy proneness and cognitive failures as correlates of dissociative amnesia. Personality and Individual Differences, 26, 961-967.

Myers, S. A. (1983). The Wilson-Barber Inventory of Childhood Memories and Imaginings: Children's form and norms for 1337 children and adolescents. Journal of Mental Imagery, 7, 83-94.

Pope, H. G., \& Hudson, J. I. (1995). Can memories of childhood sexual abuse be repressed? Psychological Medicine, 25, 121-126.

Riccio, D. C., Rabinowitz, V. C., \& Axelrod, S. (1994). Memory: When less is more. American Psychologist, 49, 917-926.

Ross, C. A. (1997). Dissociative identity disorder: Diagnosis, clinical features, and treatment of multiple personality. New York: Wiley. 
Schwarz, N. (1998). Accessible content and accessibility experiences: The interplay of declarative and experiential information in judgment. Personality and Social Psychology Review, 2, 87-99.

Spanos, N. P., Burgess, C. A., Burgess, M. F., Samuels, C., \& Blois, W. O. (1999). Creating false memories of infancy with hypnotic and non-hypnotic procedures. Applied Cognitive Psychology, 13, 201-218.

Winkielman, P., Schwarz, N., \& Belli, R. F. (1998). The role of ease of retrieval and attribution in memory judgments: Judging your memory as worse despite recalling more events. Psychological Science, 9, 124-126. 